\title{
An $\Omega-3$ fatty acid desaturase-expressing gene attenuates prostate cancer proliferation by cell cycle regulation
}

\author{
JINSHUN PAN $^{1}$, SUJIN ZHOU ${ }^{2}$, RONG XIANG ${ }^{3}$, ZHENGGANG ZHAO $^{2}$, SHANSHAN LIU $^{3}$, \\ NING DING ${ }^{3}$, SIJIA GONG ${ }^{3}$, YAN LIN $^{3}$, XIAOXI LI $^{3}$, XIAOMING BAI $^{4}$, FANGHONG LI $^{2}$ and ALLAN Z.ZHAO ${ }^{2}$ \\ ${ }^{1}$ Department of Biotherapy, The Second Affiliated Hospital, Nanjing Medical University, Nanjing, Jiangsu 210029; \\ ${ }^{2}$ Collaborative Innovation Center for Cancer Medicine, The Institute of Biomedical and Pharmaceutical Sciences, \\ Guangdong University of Technology, Guangzhou, Guangdong 510006; ${ }^{3}$ The Center of Metabolic Disease Research; \\ ${ }^{4}$ Cancer Center, Department of Pathology, Nanjing Medical University, Nanjing, Jiangsu 210029, P.R. China
}

Received October 29, 2015; Accepted October 25, 2016

DOI: $10.3892 / \mathrm{ol} .2017 .5880$

\begin{abstract}
Previous studies have reported that $\Omega-6$ and $\Omega-3$ fatty acids have opposing effects on cancer development. Consuming high levels of long-chain $\Omega-3$ polyunsaturated fatty acids (PUFAs) has been shown to reduce prostate cancer risk and increase chemotherapy sensitivity. The sdd17 gene encodes an $\Omega$-3 fatty acid desaturase, which converts arachidonic acid into eicosapentaenoic acid (EPA). However, little is known regarding the function of the sdd17 gene in tumor cells in vitro. In the present study, prostate cancer cells were infected with the msdd17 gene, which allowed the endogenous production of $\Omega-3$ PUFAs. The cells that expressed the msdd17 gene had high levels of long-chain $\Omega-3$ PUFAs compared with the control cells. Expression of the msdd17 gene significantly inhibited prostate cancer cell proliferation. EPA exposure and msdd17 gene transfection each induced G2 cell cycle arrest and reduced E2F transcription factor 1 expression in prostate cancer cells. These results suggest that msdd17 gene transfection suppressed prostate cancer cell proliferation and induced G2 cell cycle arrest.
\end{abstract}

\section{Introduction}

Prostate cancer is the fourth leading cause of cancer-associated mortality and the second most prevalent cancer worldwide (1). In developed countries, prostate cancer is the most commonly diagnosed cancer in men and affects $>17 \%$ of men worldwide (1). In the US, prostate cancer is the most common malignancy and the second leading cause of cancer-associated

Correspondence to: Professor Allan Z. Zhao, Collaborative Innovation Center for Cancer Medicine, The Institute of Biomedical and Pharmaceutical Sciences, Guangdong University of Technology, 100 Waihuan Xi Road, Guangzhou, Guangdong 510006, P.R. China E-mail: azzhao@njmu.edu.cn

Key words: $\Omega-3$ fatty acid desaturase, prostate cancer cells, proliferation, cell cycle, E2F1 mortality (2). Globally, a high incidence of prostate cancer is associated with excessive consumption of $\Omega-6$ polyunsaturated fatty acids (PUFAs), commonly found in red and organ meats, refined vegetable oils and cooked processed meat (3-5). Conversely, evidence suggests that an $\Omega-3$ PUFA-rich diet is inversely associated with prostate cancer development (6-9).

Both $\Omega-6$ and $\Omega-3$ PUFAs are essential fatty acids (10), and while $\Omega-3$ PUFAs have protective effects, $\Omega-6$ PUFAs may serve a role in cancer development (11-14). It has been demonstrated that dietary intake of long-chain $\Omega-3$ PUFAs reduces the incidence of several types of cancer and alleviates cancer-associated complications $(15,16)$. Clinically, long-term intake of dietary or supplemental docosahexaenoic acid (DHA) and eicosapentaenoic acid (EPA) (both $\Omega$-3 PUFAs) is associated with a decreased risk of prostate cancer development (6-9), increased sensitivity to chemotherapy treatment (14) and decreased risk of advanced stage disease, metastases and cancer-associated mortality $(8,17,18)$. Additionally, dietary $\Omega-3$ PUFAs enhance hormone ablation therapy in androgen-dependent prostate cancer (19) and attenuate prostate cancer growth in primary prostate cancer development (20) and xenograft models (19). Therefore, $\Omega-3$ PUFAs may be important in the prevention and treatment of prostate cancer.

The EPA-rich Saprolegnia diclina gene, sdd17, encodes an $\Omega-3$ fatty acid desaturase that converts exogenous arachidonic acid (AA), an $\Omega-6$ PUFA, into EPA (21). It has been reported that sdd17 from EPA-rich fungus is expressed at high levels and increases $\Omega-3$ fatty acid concentrations in mammalian cells (22). In the present study, prostate cancer cells were infected with a lentivirus carrying the sdd17 gene and the underlying mechanisms of $\Omega$-3 PUFAs on prostate cell proliferation were evaluated. The potential positive outcomes of the present study may benefit patients with prostate cancer.

\section{Materials and methods}

Reagents. All cell culture reagents were purchased from Incoterm Fisher Scientific, Inc. (Waltham, MA, USA). AA, EPA, propidium iodide (PI) and PUFA standards were obtained from Sigma-Aldrich; Merck Millipore (Darmstadt, 
Germany). Water-soluble tetrazolium (WST) was acquired from Dojindo Molecular Technologies, Inc. (Kumamoto, Japan). Anti-E2F transcription factor 1 antibodies (\#sc-251; dilution, 1:1,000) were obtained from Santa Cruz Biotechnology, Inc. (Dallas, TX, USA) and anti- $\beta$-actin antibodies (\#ab8226; dilution, 1:2,000) were purchased from Abcam (Cambridge, UK).

Cell culture and proliferation assays. The human prostate cancer cell line VCaP was obtained from the American Type Culture Collection (Manassas, VA, USA). VCaP cells were cultured at $37^{\circ} \mathrm{C}$ and $5 \% \mathrm{CO}_{2}$ in Dulbecco's modified Eagle's medium supplemented with $10 \%$ fetal bovine serum (Invitrogen; Thermo Fisher Scientific, Inc.), $100 \mathrm{IU} / \mathrm{ml}$ penicillin and $100 \mu \mathrm{g} / \mathrm{ml}$ streptomycin. Cell proliferation assays were performed in 96 -well plates. Cells $\left(5 \times 10^{3}\right.$ per well $)$ were incubated for $24 \mathrm{~h}$ with different concentrations of PUFAs (10-50 $\mu \mathrm{M})$, stained with WST at $37^{\circ} \mathrm{C}$ for $1 \mathrm{~h}$ and quantified at $450 \mathrm{~nm}$ (ELX800; BioTek Instruments, Inc., Winooski, VT, USA).

Overexpression of msdd17 by lentiviral transfection. The sdd17 gene was cloned from S. diclina based on its nucleotide sequence (GenBank accession no. AY373823). The codons of sdd17 cDNA were optimized for efficient translation in mammalian cells, resulting in the msdd17 gene. The msdd17 cDNA was subsequently inserted into the PLJM1 lentivirus vector (Addgene, Inc., Cambridge, MA, USA); pMD2.G and psPAX2 plasmids were co-transfected with PLJM1-msdd17 (vehicle plasmid) into $293 \mathrm{~T}$ cells (American Type Culture Collection, Manassas, VA, USA) using X-tremeGENE ${ }^{\mathrm{TM}} \mathrm{HP}$ DNA transfection reagent (Roche Diagnostics, Indianapolis, IN, USA). In order to generate a stable msdd17-overexpressing cell line, lentivirus-containing supernatant was harvested $48 \mathrm{~h}$ post-transfection and used to infect VCaP cells.

Reverse transcription-quantitative polymerase chain reaction (RT-qPCR) analysis of msdd17 gene expression levels. Total RNA was extracted using TRIzol ${ }^{\circledR}$ reagent, and was subsequently treated with DNase I and reverse transcribed using the PrimeScript $^{\mathrm{TM}}$ RT reagent kit (Takara Bio, Inc., Shiga, Japan) following the manufacturer protocol. qPCR was performed using an Applied Biosystems StepOnePlus ${ }^{\mathrm{TM}}$ Real-Time PCR system (Applied Biosystems; Thermo Fisher Scientific, Inc.). FastStart Universal SYBR Green Master (Rox) was obtained from Roche Diagnostics (\#04913914001). The qPCR conditions consisted of 1 cycle at $50^{\circ} \mathrm{C}$ for $2 \mathrm{~min}$, followed by 1 cycle at $95^{\circ} \mathrm{C}$ for $30 \mathrm{sec}$, and 40 cycles at $95^{\circ} \mathrm{C}$ for $15 \mathrm{sec}, 58^{\circ} \mathrm{C}$ for $30 \mathrm{sec}$ and $72^{\circ} \mathrm{C}$ for $30 \mathrm{sec}$. The experiments were repeated six times. The results were normalized according to the expression levels of $\beta$-actin RNA. Results were expressed using the $2^{-\Delta \Delta \mathrm{Cq}}$ method (23). The primer sequences were as follows: msdd17, forward, 5'-GTACACAAACCAAGCTCCGC-3' and reverse, 5'-CCATCCTGACCCCATTCGAG-3'; and $\beta$-actin, forward, 5'-GCTCTGGCTCCTAGCACCAT-3' and reverse, 5'-GGGCCGGACTCATCGTACT-3'.

Gas chromatography (GC) analysis. Lipid extraction from VCaP cells was performed following a previously described protocol (24). Gas chromatography was performed on an
Agilent 7890A Gas Chromatograph (Agilent Technologies, Inc., Santa Clara, CA, USA). Compounds were identified by comparing their retention times with those of PUFA standards.

Cell cycle analysis. Following incubation overnight in Dulbecco's modified Eagle's medium (Invitrogen), VCaP cells were harvested and rinsed with PBS twice. Prior to cell cycle analysis, cells were fixed in $70 \%$ pre-cold ethanol at $4^{\circ} \mathrm{C}$ overnight, and prior to flow cytometry, cells were washed twice with PBS and then resuspended with PBS containing $10 \mathrm{mg} / \mathrm{ml}$ PI (Sigma-Aldrich; Merck Millipore) and incubated for $15 \mathrm{~min}$ in the dark at room temperature. DNA content was analyzed using a BD FACStar flow cytometer and the percentages of different cell cycle phases were determined using a ModFit LT software version 4.0 (BD Biosciences, San Jose, CA, USA).

Western blotting. VCaP cells were treated with PUFA agents at $37^{\circ} \mathrm{C}$ for various times as indicated in the experiments. The cells were collected into lysis buffer [50 mM Tris- $\mathrm{HCl}(\mathrm{pH} \mathrm{8.0)}$, $150 \mathrm{mM} \mathrm{NaCl}, 0.5 \%$ sodium deoxycholate, $1 \%$ Nonidet P-40, $0.1 \% \mathrm{SDS}, 100 \mathrm{~g} / \mathrm{ml}$ PMSF and aprotinin] and placed on ice for $30 \mathrm{~min}$. Cell lysates were sonicated on ice for at least $30 \mathrm{sec}$ and then cleared by centrifugation at $12,000 \mathrm{x} g$ for $30 \mathrm{~min}$ at $4^{\circ} \mathrm{C}$. Equal amounts of total protein $(40 \mu \mathrm{g})$ were separated by SDS-PAGE and transferred onto a nitrocellulose membrane. The membranes were probed with the appropriate antibodies at $4^{\circ} \mathrm{C}$ overnight with gentle agitation. Immunoreactivity was detected by ECL and quantified using ImageLab version 4.0 analysis software (Bio-Rad Laboratories, Inc., Hercules, CA, USA).

Statistical analysis. Data are presented as the mean \pm standard error of at least three independent experiments. All statistical analyses were performed using GraphPad Prism version 5.01 (GraphPad Software, Inc., La Jolla, CA, USA) and included either two-tailed Student's $t$-test or one-way analysis of variance followed by Dunnett's test for comparing the means of two or multiple groups, respectively. $\mathrm{P}<0.05$ was considered to indicate a statistically significant difference.

\section{Results}

Effect of $\Omega-3$ PUFAs on VCaP cell growth. To assess the effects of $\Omega-3$ PUFAs on prostate cancer cells, VCaP cells were exposed to either AA or EPA. The results demonstrated that AA stimulated VCaP cell proliferation (Fig. 1A), which was consistent with previous observations in breast (24) and endometrial $(25,26)$ cancer cell lines. Conversely, EPA effectively inhibited prostate cancer cell growth in vitro. At the highest concentration $(50 \mu \mathrm{M})$, EPA caused an 8-fold reduction in VCaP cell viability (Fig. 1B), demonstrating that it inhibited $\mathrm{VCaP}$ cell viability in a dose-dependent manner.

Effect of msdd17 on VCaP cell growth. To assess the effect of msdd17 on prostate cancer cells, $\mathrm{VCaP}$ cells were infected with a lentivirus carrying the msdd17 gene (VCaP-msdd17 cells). A green fluorescent protein (GFP)-expressing line, VCaP-GFP, was generated as a control. 

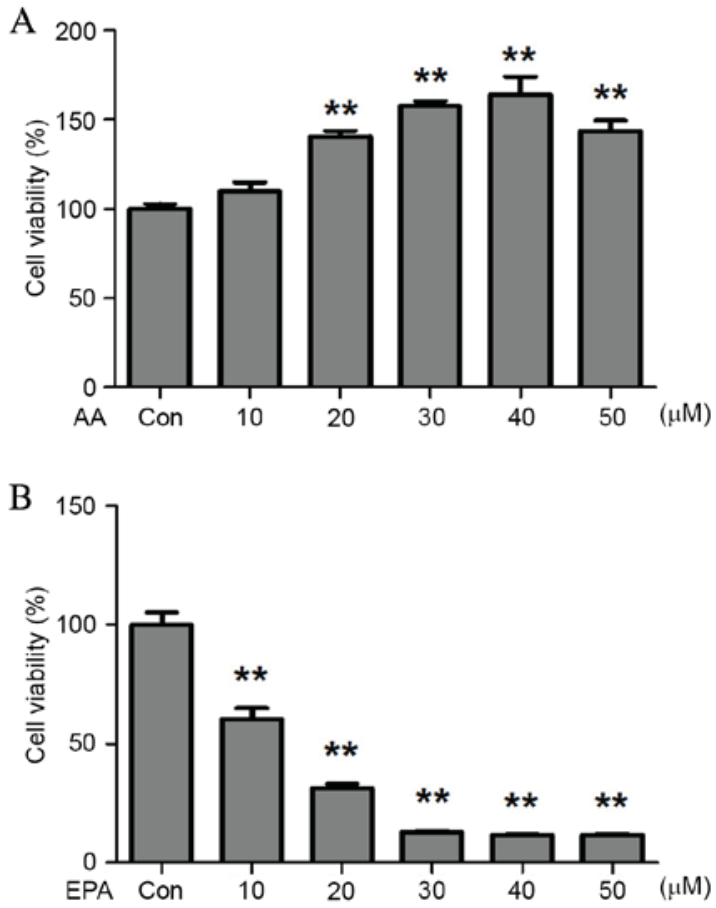

Figure 1. Effect of exogenous $\Omega-3$ polyunsaturated fatty acids on prostate cancer cell growth in vitro. $\mathrm{VCaP}$ cells grown in 96-well plates were treated with varying concentrations of (A) AA or (B) EPA. Data were analyzed by one-way analysis of variance followed by Dunnett's test. Increasing concentrations of AA increased $\mathrm{VCaP}$ cell growth, while increasing concentrations of EPA decreased cell growth. The linear trend was significant in each experiment. Data are presented as the mean \pm standard error of the mean $(n=6)$. ${ }^{* *} \mathrm{P}<0.01$ vs. control cells. AA, arachidonic acid; EPA, eicosapentaenoic acid.

The lentivirus carrying the msdd 17 gene was used to infect $\mathrm{VCaP}$ cells and the co-expression of GFP allowed the identification of the cells that expressed the msdd17 gene. Following infection with the lentivirus, the $\mathrm{VCaP}$ cells exhibited bright fluorescence indicating a high expression level of the transgene (Fig. 2). qPCR was performed to analyze msdd17 gene expression levels. The results indicated significantly increased msdd 17 expression levels in the VCaP-msdd 17 cells compared with those of the control cells (Fig. 3A), demonstrating that the msdd 17 gene may be highly expressed in transfected $\mathrm{VCaP}$ cells, which lack the gene naturally.

Msdd17 gene transfection resulted in the conversion of $\Omega-6$ PUFAs into $\Omega-3$ PUFAs in the VCaP cells (Table I). GC analyses demonstrated that $26 \%$ of AA was converted into EPA (Table I). Consistent with this observation, msdd17 gene expression significantly suppressed $\mathrm{VCaP}$ cell viability (Fig. 3B). Taken together, these results indicated that endogenous EPA, mediated by msdd 17 gene expression, directly inhibited prostate cancer cell growth.

Effect of msdd17 on VCaP cell cycle. Flow cytometry analyses demonstrated that msdd17 gene expression resulted in G2 arrest in the cell cycle of VCaP cells (Table II). To assess the mechanism by which $\Omega-3$ PUFAs suppress cell proliferation through cell cycle arrest, the expression of E2F1 was evaluated following EPA treatment. Western blot analysis demonstrated that EPA treatment significantly decreased E2F1 expression and that the expression of msdd17 mimicked the effect of EPA on E2F1 regulation (Fig. 4).
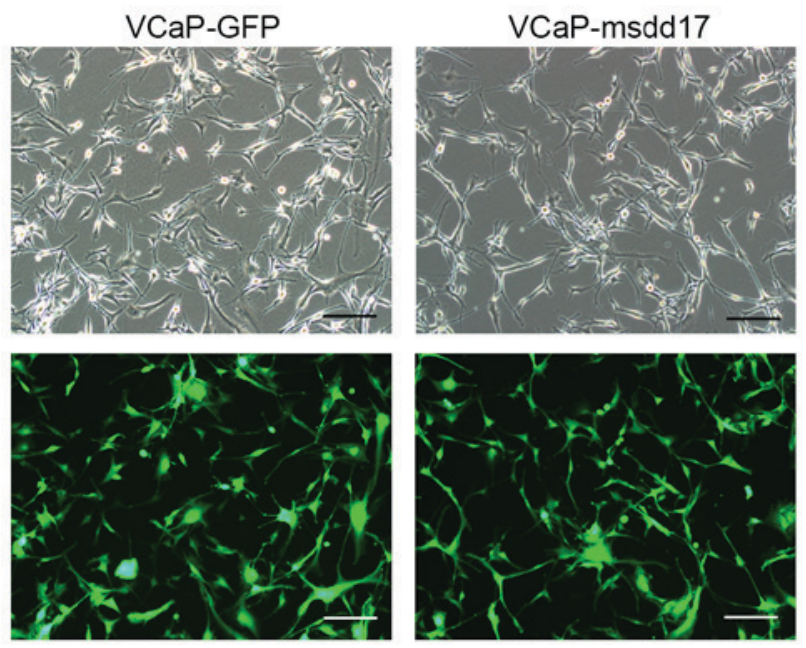

Figure 2. Micrographs of VCaP cells expressing GFP. Human VCaP cells were infected with a lentivirus carrying the msdd17 gene (right) or control lentivirus (left). Green fluorescence was visualized with bright light (upper) and blue light (lower). Visualization of GFP co-expression demonstrates that the msdd17 gene is highly expressed in infected cells. Scale bars, $100 \mu \mathrm{m}$. GFP, green fluorescent protein.
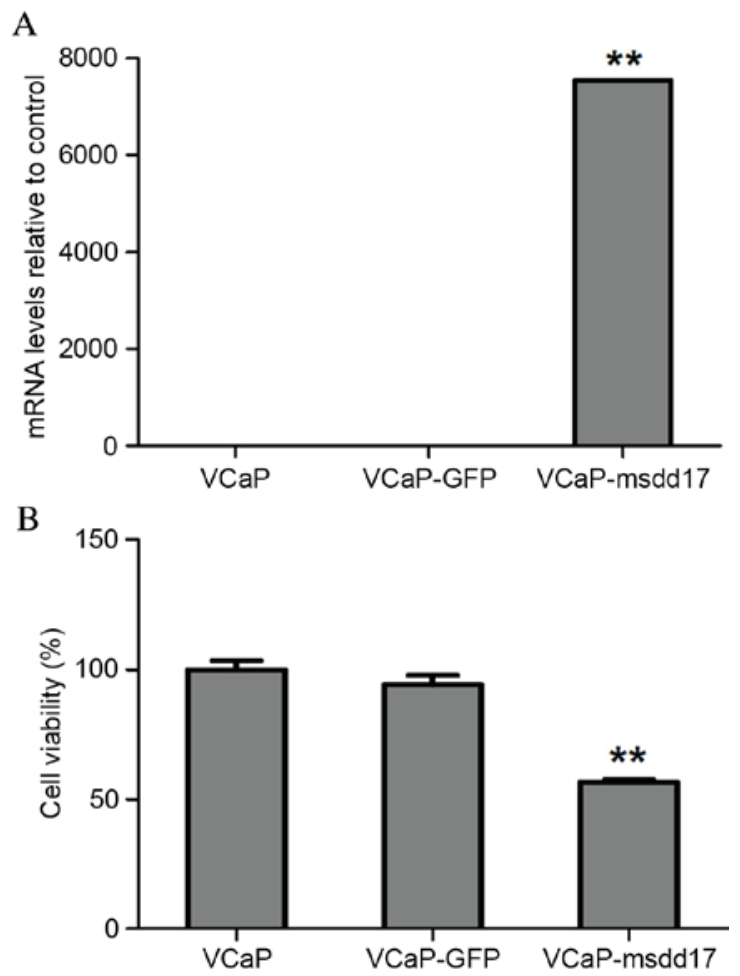

Figure 3. Effect of endogenously produced eicosapentaenoic acid on prostate cancer cell growth in vitro. (A) msdd17 gene expression in $\mathrm{VCaP}-\mathrm{msdd} 17$ cells compared with controls, based on reverse transcription-quantitative polymerase chain reaction analyses. (B) VCaP-GFP and VCaP-msdd17 cells were subjected to cell growth assays. The msdd17 gene significantly inhibited cell viability. ${ }^{* *} \mathrm{P}<0.01$ vs. control cells. Data are presented as the mean \pm standard error of the mean $(n=6)$. GFP, green fluorescent protein.

\section{Discussion}

It is well known that $\Omega$-3 PUFAs have tumor-suppressing effects. The msdd17 gene, which encodes an $\Omega-3$ fatty acid desaturase, converts AA into EPA $(21,22)$. However, little is 
Table I. $\Omega-6$ and $\Omega-3$ PUFA levels in VCaP-msdd17 cells compared with controls.

\begin{tabular}{lcc}
\hline PUFAs, $\%$ & VCaP-GFP & VCaP-msdd17 \\
\hline LA $(\mathrm{C} 18: 2, \Omega-6)$ & $1.21 \pm 0.06$ & $1.23 \pm 0.30$ \\
AA $(\mathrm{C} 20: 4, \Omega-6)$ & $6.21 \pm 0.12$ & $4.57 \pm 0.07^{\mathrm{a}}$ \\
ALA $(\mathrm{C} 18: 3 \Omega-3)$ & $0.16 \pm 0.00$ & $0.15 \pm 0.02$ \\
EPA $(\mathrm{C} 20: 5, \Omega-3)$ & $1.20 \pm 0.02$ & $1.64 \pm 0.02^{\mathrm{a}}$ \\
DPA $(\mathrm{C} 22: 5, \Omega-3)$ & $2.97 \pm 0.12$ & $4.63 \pm 0.05^{\mathrm{a}}$ \\
DHA $(\mathrm{C} 22: 6, \Omega-3)$ & $6.67 \pm 0.55$ & $7.15 \pm 0.09$
\end{tabular}

${ }^{\mathrm{a}} \mathrm{P}<0.01 . \Omega-6$ and $\Omega-3$ PUFA levels were determined using standard protocols (see Materials and methods). $\Omega-6$ and $\Omega-3$ PUFAs are expressed as a percentage of all fatty acid peaks, i.e. the distribution areas of different $\Omega-3$ or $\Omega-6$ PUFAs peaks divided by the total peak areas of all detectable saturated and unsaturated free fatty acids (from the same sample) obtained from gas chromatography analyses. Data are presented as the mean \pm standard error of the mean $(n=6)$. PUFA, polyunsaturated fatty acids; GFP, green fluorescent protein; LA, linoleic acid; AA, arachidonic acid; LA, $\alpha$-lipoic acid; EPA, eicosapentaenoic acid; PA, docosapentaenoic acid; DHA, docosahexaenoic acid.

Table II. Flow cytometry analyses of cell cycle in VCaP cells.

\begin{tabular}{lccc}
\hline & G1/G0,\% & S, \% & G2/M, \% \\
\hline VCaP-GFP & $80.96 \pm 1.02$ & $10.12 \pm 0.90$ & $8.92 \pm 0.31$ \\
VCaP-msdd17 & $81.22 \pm 3.35$ & $3.40 \pm 1.83^{\mathrm{a}}$ & $15.38 \pm 1.53^{\mathrm{a}}$ \\
EPA & $78.98 \pm 2.62$ & $3.81 \pm 1.18^{\mathrm{a}}$ & $17.21 \pm 1.47^{\mathrm{a}}$ \\
\hline
\end{tabular}

${ }^{\mathrm{a}} \mathrm{P}<0.05$. VCaP cells grown in 6 -well plates were harvested for cell cycle analyses. Data are presented as the mean \pm standard error of the mean $(n=4)$. EPA, eicosapentaenoic acid; GFP, green fluorescent protein.

known regarding the function of the msdd17 gene in tumor cells in vitro. Therefore, the present study aimed to investigate the effect and underlying mechanisms of the msdd17 gene on prostate cancer. The msdd17 gene was transfected directly into $\mathrm{VCaP}$ cells and the inhibitory effects of the gene on prostate cancer cell proliferation was confirmed. Further experiments demonstrated that msdd17 gene expression induced G2 cell cycle arrest in prostate cancer cells and that E2F1 may be associated with this process. To the best of our knowledge, these results demonstrate, for the first time, that msdd17 gene transfection into prostate cancer cells may be used as a novel therapeutic strategy to treat prostate cancer.

Mounting evidence has linked the dietary consumption of $\Omega$-3 PUFAs with the prevention or attenuation of several types of cancer, including breast (27), endometrial (28) and prostate (6-9) cancer. In the present study, $\mathrm{VCaP}$ cells were exposed to either AA or EPA, and it was demonstrated that while EPA inhibited prostate cancer cell proliferation in a dose-dependent manner, AA stimulated cell proliferation. $\mathrm{GC}$ analyses indicated an association between msdd17 gene expression and the successful conversion of AA into EPA.

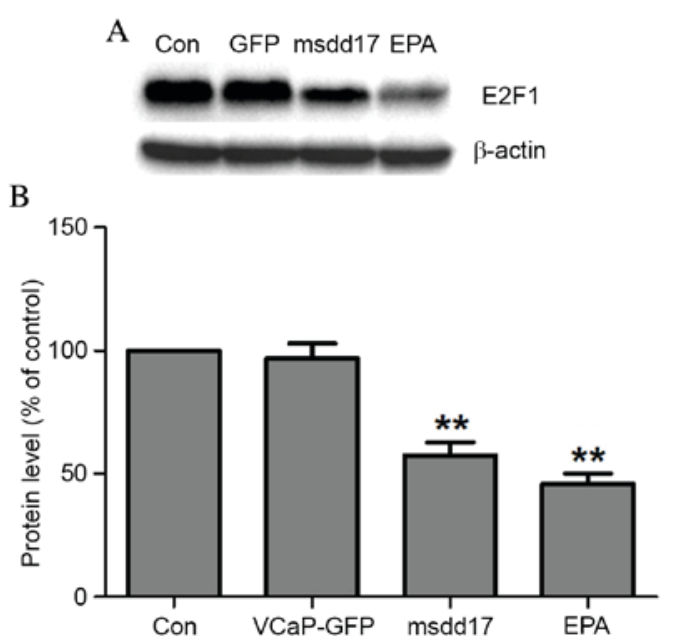

Figure 4. Exogenously and endogenously produced EPA induced E2F1-mediated prostate cancer cell G2 arrest in vitro. (A) E2F1 was detected by western blotting. VCaP, VCaP-GFP and VcaP-msdd17 cells were cultured without serum for $12 \mathrm{~h}$ and exposed to $50 \mu \mathrm{M}$ EPA for $24 \mathrm{~h} .{ }^{* *} \mathrm{P}<0.01$ vs. $\mathrm{VCaP}$ cells. (B) Data are presented as the mean \pm standard error of the mean $(n=3)$. EPA, eicosapentaenoic acid; E2F1, E2 transcription factor 1; GFP, green fluorescence protein.

Additionally, cell proliferation assays demonstrated that msdd17 gene expression inhibited the proliferation of prostate cancer cells. Therefore, expression of the msdd17 gene may suppress tumorigenesis by simultaneously increasing endogenous EPA levels and decreasing endogenous AA levels.

$\mathrm{E} 2 \mathrm{~F} 1$ is a transcription factor involved in the $\mathrm{pRb} / \mathrm{E} 2 \mathrm{~F} 1$ pathway and in cell cycle regulation (29), and it enhances glycolysis by suppressing Sirt6 transcription in prostate cancer cells (30). Previous studies have reported that G2/M cell cycle arrest is associated with the downregulation of E2F1 (31-33). In the present study, cell cycle analyses indicated that EPA and msdd17 gene expression inhibited prostate cancer cell proliferation by inducing prostate cancer G2 cell cycle arrest. As E2F1 serves a critical role in cellular proliferation, differentiation and apoptosis $(34,35)$, the present study investigated whether E2F1 was involved in msdd17 gene expression-induced cell proliferation arrest in prostate cancer cells. The results demonstrated that msdd17 gene expression and exogenous EPA treatment significantly decreased E2F1 expression.

In conclusion, to the best of our knowledge, the present study is the first to evaluate the function of the msdd17 gene in tumor cells in vitro. The msdd 17 gene inhibited prostate cancer cell proliferation by regulating the prostate cancer cell cycle. Therefore, stimulating the conversion of AA into EPA may be an effective therapeutic approach to treat prostate cancer.

\section{Acknowledgements}

The present study was supported by grants from the National Basic Research Program of China (973 Program; grant no. 2013CB945202), the National Natural Science Foundation of China (grant nos. 81630021 and 81170780 to A.Z., 81372798 to F.L. and 81200570 to L.X.), the Ph.D. Programs Foundation of Ministry of Education of China (grant no. 20113234110005), the Scientific Support Program of Jiangsu Province (grant no. BE2012756), the Natural Science Foundation of Jiangsu 
Province of China (grant nos. BK20130059 and 2011766), the Natural Science Foundation of Nanjing Medical University (grant no. 2016NJMUZD027 to J.P.), the Young Medical Talents of Jiangsu Province (grant no. QNRC2016663 to J.P.), and the High-level Innovative Talents Reward from Jiangsu Province (to F.L.).

\section{References}

1. Torre LA, Bray F, Siegel RL, Ferlay J, Lortet-Tieulent J and Jemal A: Global cancer statistics, 2012. CA Cancer J Clin 65: 87-108, 2015

2. Siegel RL, Miller KD and Jemal A: Cancer statistics, 2015. CA Cancer J Clin 65: 5-29, 2015.

3. Apte SA, Cavazos DA, Whelan KA and Degraffenried LA A low dietary ratio of omega- 6 to omega-3 Fatty acids may delay progression of prostate cancer. Nutr Cancer 65: 556-562, 2013

4. Rodriguez C, McCullough ML, Mondul AM, Jacobs EJ, Chao A, Patel AV, Thun MJ and Calle EE: Meat consumption among Black and White men and risk of prostate cancer in the cancer prevention study II nutrition cohort. Cancer Epidemiol Biomarkers Prev 15: 211-216, 2006.

5. Walker M, Aronson KJ, King W, Wilson JW, Fan W, Heaton JP, MacNeily A, Nickel JC and Morales A: Dietary patterns and risk of prostate cancer in Ontario, Canada. Int J Cancer 116: 592-598, 2005.

6. Hedelin M, Chang ET, Wiklund F, Bellocco R, Klint A, Adolfsson J, Shahedi K, Xu J, Adami HO, Grönberg H and Bälter KA: Association of frequent consumption of fatty fish with prostate cancer risk is modified by COX-2 polymorphism. Int J Cancer 120: 398-405, 2007.

7. Norrish AE, Skeaff CM, Arribas GL, Sharpe SJ and Jackson RT: Prostate cancer risk and consumption of fish oils: A dietary biomarker-based case-control study. Br J Cancer 81: 1238-1242, 1999.

8. Leitzmann MF, Stampfer MJ, Michaud DS, Augustsson K, Colditz GC, Willett WC and Giovannucci EL: Dietary intake of n-3 and n- 6 fatty acids and the risk of prostate cancer. Am J Clin Nutr 80: 204-216, 2004

9. Pham TM, Fujino Y, Kubo T, Ide R, Tokui N, Mizoue T, Ogimoto I, Matsuda S and Yoshimura T: Fish intake and the risk of fatal prostate cancer: Findings from a cohort study in Japan. Public Health Nutr 12: 609-613, 2009.

10. Simopoulos AP: The importance of the omega-6/omega-3 fatty acid ratio in cardiovascular disease and other chronic diseases Exp Biol Med (Maywood) 233: 674-688, 2008.

11. de Lorgeril M and Salen P: New insights into the health effects of dietary saturated and omega- 6 and omega- 3 polyunsaturated fatty acids. BMC Med 10: 50, 2012.

12. Berquin IM, Edwards IJ and Chen YQ: Multi-targeted therapy of cancer by omega-3 fatty acids. Cancer Lett 269: 363-377, 2008.

13. Patel MI, Kurek C and Dong Q: The arachidonic acid pathway and its role in prostate cancer development and progression. J Urol 179: 1668-1675, 2008

14. Hajjaji N and Bougnoux P: Selective sensitization of tumors to chemotherapy by marine-derived lipids: A review. Cancer Treat Rev 39: 473-488, 2013.

15. Larsson SC, Kumlin M, Ingelman-Sundberg $M$ and Wolk A: Dietary long-chain n-3 fatty acids for the prevention of cancer: A review of potential mechanisms. Am J Clin Nutr 79: 935-945, 2004.

16. Azrad M, Turgeon C and Demark-Wahnefried W: Current evidence linking polyunsaturated Fatty acids with cancer risk and progression. Front Oncol 3: 224, 2013.

17. Fradet V, Cheng I, Casey G and Witte JS: Dietary omega-3 fatty acids, cyclooxygenase-2 genetic variation, and aggressive prostate cancer risk. Clin Cancer Res 15: 2559-2566, 2009.

18. Pelser C, Mondul AM, Hollenbeck AR and Park Y: Dietary fat, fatty acids, and risk of prostate cancer in the NIH-AARP diet and health study. Cancer Epidemiol Biomarkers Prev 22: 697-707, 2013.
19. McEntee MF, Ziegler C, Reel D, Tomer K, Shoieb A, Ray M, Li X, Neilsen N, Lih FB, O'Rourke D and Whelan J: Dietary n-3 polyunsaturated fatty acids enhance hormone ablation therapy in androgen-dependent prostate cancer. Am J Pathol 173: 229-241, 2008.

20. Berquin IM, Min Y, Wu R, Wu J, Perry D, Cline JM, Thomas MJ, Thornburg T, Kulik G, Smith A, et al: Modulation of prostate cancer genetic risk by omega-3 and omega- 6 fatty acids. J Clin Invest 117: 1866-1875, 2007.

21. Pereira SL, Huang YS, Bobik EG, Kinney AJ, Stecca KL, Packer JC and Mukerji P: A novel omega3-fatty acid desaturase involved in the biosynthesis of eicosapentaenoic acid. Biochem J 378: 665-671, 2004.

22. Chen Y, Zhang M and Gou K: SDD17 desaturase can convert arachidonic acid to eicosapentaenoic acid in mammalian cells. Biochem Biophys Res Commun 394: 158-162, 2010.

23. Livak KJ and Schmittgen TD: Analysis of relative gene expression data using real-time quantitative PCR and the 2(-Delta Delta C(T)) Method. Methods 25: 402-408, 2001.

24. Chen Z, Zhang Y, Jia C, Wang Y, Lai P, Zhou X, Song Q, Lin J, Ren Z, Gao Q, et al: mTORC1/2 targeted by $n-3$ polyunsaturated fatty acids in the prevention of mammary tumorigenesis and tumor progression. Oncogene 33: 4548-4557, 2014.

25. Pan J, Cheng L, Bi X, Zhang X, Liu S, Bai X, Li F and Zhao AZ: Elevation of $\omega-3$ polyunsaturated fatty acids attenuates PTEN-deficiency induced endometrial cancer development through regulation of COX-2 and PGE2 Production. Sci Rep 5: $14958,2015$.

26. Zheng H, Tang H, Liu M, He M, Lai P, Dong H, Lin J, Jia C, Zhong M, Dai Y, et al: Inhibition of endometrial cancer by n-3 polyunsaturated fatty acids in preclinical models. Cancer Prev Res (Phila) 7: 824-834, 2014.

27. Gago-Dominguez M, Yuan JM, Sun CL, Lee HP and Yu MC: Opposing effects of dietary n-3 and n-6 fatty acids on mammary carcinogenesis: The Singapore Chinese Health Study. Br J Cancer 89: 1686-1692, 2003.

28. Arem H, Neuhouser ML, Irwin ML, Cartmel B, Lu L, Risch H, Mayne ST and Yu H: Omega-3 and omega-6 fatty acid intakes and endometrial cancer risk in a population-based case-control study. Eur J Nutr 52: 1251-1260, 2013.

29. Chen HZ, Tsai SY and Leone G: Emerging roles of E2Fs in cancer: An exit from cell cycle control. Nat Rev Cancer 9: 785-797, 2009.

30. Wu M, Seto E and Zhang J: E2F1 enhances glycolysis through suppressing Sirt6 transcription in cancer cells. Oncotarget 6: 11252-11263, 2015.

31. Maudet C, Mano M, Sunkavalli U, Sharan M, Giacca M, Förstner KU and Eulalio A: Functional high-throughput screening identifies the miR-15 microRNA family as cellular restriction factors for Salmonella infection. Nat Commun 5: 4718,2014

32. Jaganathan A, Chaurasia P, Xiao GQ, Philizaire M, Lv X, Yao S, Burnstein KL, Liu DP, Levine AC and Mujtaba S: Coactivator MYST1 regulates nuclear factor- $\kappa \mathrm{B}$ and androgen receptor functions during proliferation of prostate cancer cells. Mol Endocrinol 28: 872-885, 2014.

33. Wang S, Li W, Xue Z, Lu Y, Narsinh K, Fan W, Li X, Bu Q, Wang F, Liang J, et al: Molecular imaging of p53 signal pathway in lung cancer cell cycle arrest induced by cisplatin. Mol Carcinog 52: 900-907, 2013.

34. Lee KY, Lee JW, Nam HJ, Shim JH, Song Y and Kang KW: PI3-kinase/p38 kinase-dependent E2F1 activation is critical for Pin1 induction in tamoxifen-resistant breast cancer cells. Mol Cells 32: 107-111, 2011.

35. Gomez-Gutierrez JG, Garcia-Garcia A, Hao H, Rao XM, Montes de Oca-Luna R, Zhou HS and McMasters KM: Adenovirus-mediated expression of truncated E2F-1 suppresses tumor growth in vitro and in vivo. Cancer 116: 4420-4423, 2010. 